\title{
EXPERIMENTAL AND CLINICAL HOMOTRANSPLANTATION OF THE LIVER
}

\author{
T. E. Starzl ${ }^{\dagger}$, T. L. Marchioro, R. T. Huntley, D. Rifkind, D. T. Rowlands, Jr. T. C. Dickinson, \\ and W. R. Waddell \\ Departments of Surgery, Pathology, and Medicine, University of Colorado Medical Center and \\ Veterans Administration Hospital, Denver, Colo
}

\begin{abstract}
Until the present time, whole-organ hepatic homotransplantation has been a disappointing procedure, both in experimental animals and in man. The operation itself carries a high immediate risk, especially in the dog, which is peculiarly subject to an anoxic hepatic injury termed "outflow block." In reported canine experiments, the majority of animals have failed to recover from the acute effects of operation. Because of the fact that it has not been possible to obtain a consistently satisfactory preparation, evaluations of the efficacy of immunosuppressive regimens for the prevention of rejection have never been published.

In the following remarks, attention will be directed to the influence of therapy with azathioprine, or azathioprine plus prednisone, upon the rejection process in dogs and in five patients receiving hepatic homografts after removal of their own livers. Since efforts to obtain long-term survival were eventually futile in both groups, an analysis of the reasons for failure will be attempted. Finally, alternative solutions will be presented which are designed to avoid the many pitfalls that have thus far precluded success.
\end{abstract}

\section{Orthotopic Homotransplantation in Dogs Using Living Donors}

Twenty-five dogs had replacements of their own livers with hepatic homografts obtained from living canine donors, employing a previously described technique. ${ }^{1}$ The donor organs were removed from healthy animals, which had been cooled to $30-32^{\circ} \mathrm{C}$. At the moment the hepatic arterial circulation was interrupted, perfusion of the liver was begun with chilled lactated Ringer's solution $\left(10-15^{\circ} \mathrm{C}\right.$.) through the portal vein. The inferior vena caval and portal systems of the recipient dog, which must be temporarily occluded during insertion of the liver, were joined with a temporary portacaval anastomosis and then decompressed with a single external by-pass (FIGURE 1 ) from the inferior to the superior vena caval systems. ${ }^{1}$ The upper vena caval, lower vena caval, hepatic arterial, and portal venous anastomoses were done in that order, and the temporary portacaval anastomosis subsequently taken down so that the vascular supply to the homograft was essentially normal. ${ }^{1}$ Internal biliary drainage was provided with a loop cholecystenterostomy. Two to $10 \mathrm{mg} . / \mathrm{kg}$. per day of azathioprine were given postoperatively to all animals (FIGURES 2 and 3), supplemented in a few cases with 20 to $100 \mathrm{mg}$. per day of subcutaneous prednisolone or prednisone (FIGURE 3).

Eleven of the 25 animals lived for less than three days after operation (TABLE 1). Ten of the early deaths were due to hemorrhage, either into the peritoneal cavity or the

\footnotetext{
*Aided by Grants A-6283, A-6344, HE07735, AM 07772, AI 04152, and OG 27 from the U. S. Public Health Service.

${ }^{\dagger}$ Markle Scholar.
} 
gastrointestinal tract, and in all of these cases there was some evidence of hepatic outflow block. With this syndrome, the liver becomes swollen and congested, and frequently hemorrhagic gastroenteritis develops, which is presumably due to acute portal hypertension resulting from the vascular abnormality within the liver. Two animals had pulmonary emboli, findings which presaged a series of unexpected complications encountered in later clinical experience. It will be noted (TABLE 1) that many of the animals which failed to survive the operation had longer ischemic intervals than those with a more benign course.

The remaining 14 animals lived for 3 to 31 days. In approximately two-thirds of these dogs, death ultimately resulted from pneumonia (TABLE 1); other causes were perforated gastric ulcer, peritonitis, liver abscess, or intussusception. Rejection per se was not a clearly demonstrable factor in the inability to obtain longer survivors. The characteristic sequence of rejection observed in untreated animals, in which hepatic failure is invariably manifest after four to six days, ${ }^{2-4}$ was prevented by the immunosuppressive regimen (FIGURES 2 and 3). Jaundice was late in onset (FIGURE 3), or was prevented altogether (FIGURE 2) in virtually every case. Cyclic changes were observed in the serum SGOT and alkaline phosphatase (FIGURES 2 and 3), and alterations in an abnormal direction were sometimes reversed with the addition of prednisolone (FIGURE 3).

In contrast to the extensive structural disorganization seen in untreated animals, ${ }^{2,3,5,6}$ the hepatic parenchyma was usually well preserved, both in those animals dying at an early (FIGURE 4) and at a later time (FIGURE 5). In specimens obtained after one week, there was often a minimal mononuclear cellular infiltrate which was concentrated in the intrahepatic periportal areas; and in many of the livers, there were focal areas of necrosis, which were most frequently near the central vein (FIGURES 4 and 5). Extensive loss of hepatocytes was observed in only three instances: one after 9, another after 20, and the third after 31 days (FIGURE $5 b$ ).

The evidence of good hepatic function in the early postoperative period of these dogs is noteworthy, in view of the observations to be reported in the following sections. Prominent early bilirubinemia or sharp rises in serum SGOT or alkaline phosphatase occurred only rarely.

Coagulation studies were performed in eight animals. Euglobulin lysis time decreased on an average of 63 per cent (indicating the presence of circulating fibrinolysis) during or just after completion of transplantation, with rebound to 108 to 318 per cent of control within 24 hours. Slight drops in fibrinogen were seen during operation, the average decline being 15 per cent of control. Transient rises in thrombin time occurred, lasting only a few hours.

\section{Canine Homotransplantation With Cadaveric Livers}

Ten dogs had replacement of their own livers with hepatic homografts, which were obtained from recently sacrificed normal dogs. These experiments were reported fully in a previous publication, ${ }^{7}$ and are summarized in TABLE 2 . Briefly, the dog cadavers were perfused with an extracorporeal hypothermic perfusion system beginning from 1 to 22 minutes after death and continuing for one to eight hours before removal and insertion of the homograft. The technique of the actual transplantation, and the postoperative care were comparible to that described in the preceding section.

Half of the animals did not survive the operative procedure, the invariable cause of death being hemorrhage, usually in association with hepatic outflow block. Survival beyond five days could not be obtained (TABLE 2), hemorrhage also accounting for three of the five delayed deaths. 
There was evidence of profound acute liver injury in every case. Sharp rises in serum SGOT, alkaline phosphatase, and bilirubin were seen immediately after operation (FIGURE 6), changes which were not commonly observed in those animals which received homografts from living donors.

Histologic studies of the homografts in these dogs showed the hepatic congestion and central necrosis which are characteristic of outflow block. Cellular infiltration was not prominent.

The difference in function between those animals which received cadaveric, as opposed to high quality homografts from living donors, is of interest, especially in relation to clinical application. The use of cadaveric organs, even under highly controlled laboratory circumstances, has not resulted in the procurement of consistently good hepatic tissue. The difference in results obtained in this series, as compared to those reported in the preceding section, demonstrate the importance of employing minimally damaged livers for hepatic transplantation.

\section{Auxiliary Liver Homograft}

Hepatic homografts were transplanted to the lower abdomen in 13 animals after the method of Goodrich and his associates, ${ }^{8}$ without removal of the dogs' own livers (FIGURE 7). The hepatic artery was connected end-to-end to the left common iliac artery or end-to-side with the aorta. The portal vein was anastomosed to the terminal vena cava and the hepatic venous outflow to the infrarenal inferior vena cava (FIGURE 7). Internal biliary drainage was provided with a cholecystoduodenostomy. The homografts were obtained from living donors as described in the first section of this paper. Mean ischemia was 35.5 minutes. Methods of immunosuppression were comparable to that in the other types of canine homotransplantation as previously described.

Postoperatively, studies of the vascular supply to the homografts were performed in nine animals after 20 to 28 days by transfemoral dye injection. In those dogs with patent vascular anastomoses, both the arterial and venous supply were relatively intact out to peripheral intrahepatic branches (FIGURE 8), although the outline of the liver was invariably noted to be smaller than had been the case at the time of its insertion. The dye passed freely through the hepatic vascular bed without holdup. The hepatic arterial supply was demonstrated to be patent in all 13 animals, either angiographically or at autopsy. The portal vein was patent in eight and occluded in five cases (TABLE 3).

In four dogs, the recipient's own liver was removed 27 to 28 days later (FIGURE 9), with a previously described technique. ${ }^{9}$ Special efforts were not made to provide constant intravenous glucose infusion postoperatively. All four animals died within 12 to 48 hours, although two awoke from pentobarbitol anesthesia. At autopsy, no explanation for death could be found, and it was concluded that the animals died of hepatic insufficiency. Hemorrhage, such as that which invariably follows total hepatectomy, had not occurred.

Seven other animals died from a variety of causes from 13 to 27 days after homotransplantation, most commonly after anesthesia for biopsy or angiography. Two dogs are alive after 35 and 42 days (TABLE 3 ).

Although there were quantitative differences, the biochemical determinations followed a similar pattern in every animal. Invariably, rises in plasma fibrinogen occurred during the first few days after transplantation (FIGURE 10), to as high as 1,000 mg. per cent, with usual return to control values. Rises in SGOT and alkaline phosphatase were seen at an early time with later return toward normal (FIGURE 10). Jaundice developed in only one animal. 
In all 13 cases, the homografts were much smaller at the time of reoperation for biopsy or recipient hepatectomy than had been the case at the time of transplantation, the gross estimate usually being that the hepatic homograft mass was reduced to 50 per cent. Weights ranged from 150 to 400 grams. Nevertheless, the gross appearance of the homograft was that of a relatively normal but diminutive organ.

All the homografts had some varying histologic evidence of rejection, a representative example being shown in FIGURE 11. There were periportal aggregates of mononuclear cells. Hepatic architecture was recognizable in all but multiple areas of focal necrosis were present which, in some cases, were very extensive. The dog's own liver was normal in four of the 13 days (FIGURE 11a). In the others, there were acute changes in the host liver which ranged grossly from discoloration to extensive areas of patchy necrosis. Histologically, there were a variety of changes, including focal necrosis, bile duct proliferation, fatty metamorphesis, and focal hemorrhage.

\section{Human Homografts after Recipient Hepatectomy}

Five patients have been treated with hepatic homografts after removal of their own diseased livers. The indications for operation were congenital biliary atresia in one case, and primary malignancy of the liver in the other four. The first patient, a three-year-old child, died on the operating table of uncontrollable hemorrhage. The last four lived for 6 to 23 days. The surgical techniques (FIGURE 12), methods of organ preservation, details of immunosuppressive therapy, causes of death, and the pathologic studies have all been previously reported. ${ }^{10,11}$ The salient features of the cases are recapitulated in TABLE 4 . In treating these patients, important additional aspects of liver transplantation were noted which had either not been recognized or were not present in the earlier work with dogs. Principal emphasis in the following remarks will be given to such new observations.

Not surprising was the much greater durability of the human compared to the dog liver homograft. In the animal experiments described in the preceding section, it was pointed out that even relatively minor degrees of ischemic injury led to the syndrome of "outflow block," and that it was impossible to obtain survival for more than a few days with the use of cadaveric dog donors. In contrast, acute hepatic congestion was not noted in any of the human homografts, despite the facts that the cadaveric sources from which they were obtained were far from ideal (TABLE 4), and that the intervals from donor death to revascularization in the recipient ranged from two and one-half to seven hours. The magnitude of acute damage to these organs varied, but it was considerable in each instance as evidenced by sharp rises in serum SGOT and early bilirubinemia (FIGURE 13), the early rises in SGOT ranging from 400 to more than 2,000 S-F units, and the bilirubin levels rising to as high as $42 \mathrm{mg}$. per cent.

While it is encouraging to note the biochemical evidence of reversibility of the ischemic effects (FIGURE 13), the degree to which the early hepatic injury contributed to the late unsuccessful outcome cannot be ascertained with certainty, although it seems certain that the present means of organ procurement are a serious deterrent to success, as was demonstrated in the previous section with more controlled experimental conditions.

A technical detail which proved to be unessential in man was the need for decompression of the nonhepatic splanchnic bed. In the dog, failure to provide perfect drainage of the portal system during the actual transplantation results in irreversible injury to the intestinal tract within a few minutes. In man, this was not found to be the case. Portal venous diversion with an external by-pass was not achieved in any of the patients and was not even attempted in three instances. No harmful result was noted. An effective by-pass from the inferior to the 
superior vena caval systems appears to be all that is necessary in man during short-term occlusion of the portal vein and inferior vena cava.

One case was of special interest because of the use of a homograft from a patient who had different $\mathrm{ABO}$ type than the recipient. The direction of tissue transfer was from $\mathrm{O}$ to $\mathrm{A}$, an incompatibility which had been demonstrated to be relatively safe in the performance of renal transplantation inasmuch as the homograft is not placed in contact with preformed host hemagglutinins. ${ }^{12,13}$ With hepatic homografts, such a breach of blood group incompatibility may be less safe, since the liver possesses erythroclastic activity ${ }^{14}$ and might react against the recipient red cells. A graft-versus-host reaction under these circumstances is a distinct possibility, manifesting as a hemolytic reaction. In the case cited, however, no evidence of a hemolysis was observed, and the homograft tissue studied at autopsy (FIGURE 14) was comparable to that seen in the other cases. Nevertheless, the use of other than matched donors and recipients must be viewed as a potentially dangerous practice.

Several complications were encountered in the human series, which were less commonly noted in the dogs. Three patients eventually developed gastrointestinal ulceration, and in these cases, gastrointestinal hemorrhage was a contributing cause of death. In addition, thoracic complications were observed in each of the four patients who survived operation. In three of these, the underlying etiology was multiple pulmonary embolization, as will be discussed below. In a fourth patient (Case 5), massive pleural effusions developed during the last few days of life, which may have been secondary to reaction around the subdiaphragmatic homograft or to the biliary peritonitis, which was the immediate cause of death.

It has already been noted that changes in the coagulation mechanism can be demonstrated during and after hepatic transplantation in animals, consisting of transient rises in fibrinolysins, declines in plasma fibrinogen, and elevation in thrombin time. What was not appreciated from the dog studies was that this acute phase of defective coagulation was succeeded by a state of hypercoagulability. This was observed in three of the four patients who survived the operative procedure, being first documented as early as one day after operation. Euglobulin lysis times became prolonged to as much as 24 hours (normal, two to four hours). Hyperfibrinogenemia also occurred at this time in three of the four cases (to as high as $600 \mathrm{mg}$. per cent). One patient (Case 4) developed phlegmasia cerulea dolens while still on the operating table after ligation of the superficial femoral vein at the site of insertion of the external by-pass. In Cases 2, 3, and 4, the patients died from multiple pulmonary emboli, which apparently originated from thrombotic sites in the inferior vena caval and ileofemoral systems. The clots had evidently formed during the hypercoagulable phase.

In all but Case 5, measures were taken during the operation to prevent the fibrinolysis and hypofibrinogenemia which was known to occur at this time, administering fresh blood, human fibrinogen ( 8 to 20 grams), and $0.1 \mathrm{gm} . / \mathrm{kg}$. epsilon aminocaproic acid (EACA). Although these agents were undoubtedly helpful in obtaining control of hemorrhage at the time of surgery, they probably potentiated the succeeding tendency for intravascular clotting. Therefore, in the last case, no clot promoting agents of any kind were used. Instead, the patient was heparinized at the time of the transplantation, using $2 \mathrm{mg} . / \mathrm{kg}$. intravenously. Neutralizing therapy with protamine sulphate was not given thereafter. Although the presence of fibrinolysins was demonstrated (euglobulin lysis time declined from six hours to 65 minutes) and declines in plasma fibrinogen were noted (from 220 to $65 \mathrm{mg}$. per cent) during operation, the later rebound hypercoagulability was not observed. The use of systemic heparinization caused diffuse hemorrhage at the time of operation, which required several hours to control, and the transfusion of 18 units of blood. At autopsy, 23 days later, no intravascular clots were found. 
There was evidence that the immunosuppressive regimens was effective in preventing or mitigating rejection. After the transient and often severe early abnormalities of liver function, all patients had a progressive return of liver function toward normal (FIGURE 13), although restoration of a completely normal biochemical state did not occur in any case. Histologically, the general architecture of the homografts were well preserved, although there were scattered focal mononuclear infiltrates which were concentrated at or near the portal triads (FIGURES 14 and 15). These cellular aggregates were of indeterminent nature, since they are often found in routine autopsy specimens, but their location is also that seen in early rejection in experimental animals. In two of the human liver transplants, there was some evidence of cholestasis, with deposits of intrahepatic bilirubin (FIGURE 15a), despite the fact that a patent and freely draining biliary drainage was present in all but the last one. The reticular pattern in all instances was well preserved (FIGURE 15b), with slight compression only in the last case.

The causes for failure are listed in TABLE 4 . The first patient died of operative hemorrhage. The primary factor in the deaths of patients 2,3 , and 4 was multiple pulmonary embolization. The last case had necrosis of the donor portion of the reconstructed common duct with secondary biliary peritonitis. This complication evidently developed on or about the 17th postoperative day, and had its onset with sudden abdominal pain.

\section{Discussion}

From the foregoing experiences, as well as from previous studies in which immunosuppressive therapy was not used, ${ }^{2-6,8,15}$ a number of conclusions appear to be justified concerning the requirements which must be met before livers can be transplanted with improved results. The requisites for success are more stringent and manifold than with renal homotransplantation, and the total problem is accordingly more complex.

\section{The Importance of Quality Tissue}

There is abundant evidence that one of the chief causes of early failure is the employment of damaged homografts. Although Sicular and Moore ${ }^{16,17}$ have demonstrated that metabolic activity persists in the liver for many hours after death, a well functioning organ can be obtained only with very brief periods of ischemia. In previous studies in dogs, ${ }^{1}$ using the method of initial donor hypothermia with subsequent infusion of cold electrolyte solutions, it was demonstrated that ischemia of more than 120 minutes invariably resulted in an unsuccessful outcome. In the present study, the influence of hepatic tissue injury is even more strikingly illustrated by comparison of the fate of dogs which received livers from healthy living donors with those for which cadaveric canine organs were used.

In the dog, failure to obtain optimally preserved homografts invariably results in severe hepatic injury with outflow block. The lethal characteristics of outflow block are not limited to those directly concerned with liver function. In addition, there are rapidly developing cardiovascular consequences, due first to sequestration of blood in the liver, and second, to the development of a low grade portal hypertension which appears to be the usual cause of the hemorrhagic gastroenteritis so often observed in the early postoperative period.

Several considerations are important in the procurement of suitable homografts. The source of donation is of paramount importance, as demonstrated in the dog experiments. In obtaining human homotransplants, the suitability of the donated homograft is less predictable, inasmuch as the homografts must come from cadaveric sources. Although postmortem extracorporeal hypothermic perfusion provides some protection for the cadaveric tissues, this technique can be instituted only after the blood supply has ceased for varying periods of time, and even then it provides an ineffective circulation. ${ }^{7}$ In humans, the 
syndrome of outflow block was not observed. Nevertheless, the homografts all exhibited biochemical evidence of moderately severe acute parenchymal injury.

Because of the importance of tissue injury in determining the outcome of an hepatic homografting procedure, it may be appropriate to question if cadaveric organs will ever be suitable. It is conceivable that the patient receiving an optimally preserved liver from a subhuman primate might have a better chance of survival than one receiving a severely damaged cadaveric homograft. This will be a particularly important possibility if long-term function can be obtained in those humans already treated in New Orleans and Denver with baboon or chimpanzee kidneys.

\section{Special Technical Problems}

Unique technical problems have been observed which are concerned with the splanchnic and systemic venous systems. With orthotopic homotransplantation, both the portal vein and inferior vena cava must be occluded during insertion of the homograft. In dogs, the need for venous decompression, particularly of the portal vein, is of greater importance than in humans. For this purpose, the use in dogs of a temporary portacaval shunt in combination with a single external bypass (FIGURE 1) has important advantages. Employing this technique, the suprahepatic and infrahepatic inferior vena caval anastomoses are done first. With completion of the second anastomosis, usually within 20 to 30 minutes, free drainage of both the portal and vena caval systems can be immediately reinstituted and the external by-pass can be removed. The interval of potential injury to the involved venous beds is thereby reduced to a minimum.

\section{Coagulation Changes}

The delayed hypercoagulability which occurred in the clinical cases had not been recognized in earlier animal experiments, although similar but less marked alterations were subsequently demonstrated to also occur in dogs. It is of interest that animals receiving auxiliary homografts invariably have similar sharp increases in plasma fibrinogen during the first few postoperative days, suggesting that the homograft may pass through a phase of intensified protein synthesis as has previously been demonstrated in some dogs by Kukral. ${ }^{4}$

The solution to the problems of initial bleeding and later coagulation are not yet clear, although in the last human case in which systemic heparinization was carried out during transplantation, the state of delayed hypercoagulability did not develop. In this patient, treatment with fibrinogen or EACA — agents used in the second, third, and fourth human cases-was avoided. It is probable that as little pharmacologic alteration as possible of the coagulation process should be imposed, and that clot inducing drugs should not be used.

\section{The Effectiveness of Immunosuppressive Therapy}

There have been no published reports of the effectiveness of immunosuppressive therapy in preventing rejection except for accounts of five human cases, ${ }^{10,11}$ and a few unsuccessful canine experiments in which total-body irradiation was used. ${ }^{18}$ It is of particular importance to obtain this information, inasmuch as it is conceivable that liver tissue either provides an unusually strong antigenic stimulus, or that the hepatic parenchyma is exceptionally sensitive to immunologic attack. The studies of Green, ${ }^{19}$ in which heterotransplants of various embryonic rabbit tissues were transferred to the anterior chamber of the guinea pig's eye, may have forecast the difficulties to be encountered with homografts. Growth of many tissues could be obtained after transfer to this favored site with the sole exception of the liver. 
The data in the present report do not permit a valid comparison of the ease with which rejection of the liver can be prevented as contrasted to other tissues. They do, however, suggest that prevention or mitigation of rejection may be possible. In addition to providing life sustaining and generally improving hepatic function during the period of survival, the human homografts had remarkably few histologic changes which could be interpreted as rejection. The orthotopically placed canine hepatic homografts had better function and anatomic preservation than was ever previously observed in untreated animals.

In the dogs treated with auxiliary liver homografts, survival of most of the dogs for as long as one month insured the procurement of histologic sections of homografts from hosts treated with immunosuppressive drugs during this interval. The canine homografts studied under these circumstances retained an intact architecture, although there was invariably some evidence of rejection, and the degree of parenchymal damage was frequently advanced. The anatomic damage to the homografts seemed greater than that which occurred at comparable times in experiments in which the dog's own liver was removed at the time of transplantation. Since it was also noted that rises in SGOT and alkaline phosphatase were consistently greater in the animals treated with auxiliary livers than in those which underwent concomitant hepatectomy, it is reasonable to ask if control of rejection is more difficult with the former preparation.

\section{Supportive Treatment During the Rejection Crisis}

In previous studies with renal homotransplants, it was pointed out that complete prevention of rejection is ordinarily not possible, but that reversal of the process could be accomplished with a high degree of regularity and completeness. ${ }^{20}$ The demonstration that rejection attempts can be reversed is an essential concept in the transplantation of any organ. The difficulty with which this is achieved after kidney transplantation is variable, necessitating such vigorous treatment in the more difficult cases as to endanger the life of the host. Furthermore, serious alterations in renal function occur at this time. Although the kidney is one of the vital organs, cessation or curtailment of its function can be tolerated for protracted periods because of the availability of renal dialysis facilities. The simplicity of the functional losses allows their replacement with artificial means. With the liver, the prospect of such acute temporary failure is unacceptable. The number of vital metabolic processes which would have to be replaced are numerous, and some are not fully understood as can be appreciated from the fact that the mechanism of death in animals receiving total hepatectomy has never been clearly delineated. The staggering early mortality that has occurred with experimental liver transplantation may be more a reflection of the inability of the recipient to remain alive during this phase of potentially reversible acute organ failure than an indication of the inherent impossibility of ultimately reversing the rejection.

It is possible that a solution to the rejection crisis may be in retaining the recipient liver during the early phase of recovery. With this approach, an hepatic homograft could pass through a rejection episode at a time when life sustaining function could still be provided by the host's own liver. After a state of host-graft adaptation has been established, host hepatectomy could be carried out. This approach is currently being evaluated. The early results indicate that at one month, survival is not possible with function of the homograft alone. It will be necessary to repeat the experiments with the performance of host hepatectomy after more prolonged intervals.

\section{Summary}

An analysis of the problems of hepatic homotransplantation has been presented, based upon extensive animal studies as well as upon experience with five human cases. In 35 of the dog experiments and in all of the clinical cases, recipient hepatectomy was performed 
concomitantly and the homograft was placed orthotopically in the liver fossa. In 13 additional canine transplants, the homograft was placed heterotopically in the lower abdomen.

Technically, canine homotransplantation presents special difficulties because of the need for perfect decompression of the nonhepatic splanchnic bed during placement of the homograft, and because of the propensity of the dog liver to develop venous outflow block after minor ischemic injury. These relatively species-specific problems were not encountered in clinical experience inasmuch as portal decompression proved to be unnecessary, and because outflow block did not occur, despite the extensive liver injury which was documented in each case.

The use of cadaveric livers in dogs leads inevitably to early death of the recipient. In humans, however, cadaveric homografts obtained under even less advantageous circumstances have proved to be life sustaining for as long as 23 days. Acute liver injury in man is more reversible than in dog, although the employment of seriously damaged homografts led directly to the death of one patient and may have contributed to the late mortality in all.

Changes in coagulation have been observed both in dogs and in man. During transplantation, fibrinolytic activity is measurable, plasma fibrinogen fails, and increases in thrombin time occur. This phase of potential danger from hemorrhage is succeeded by a state of hypercoagulability in the postoperative period. Multiple pulmonary emboli which caused the death of three patients were thought to have originated during this time. Suggestions are submitted for the management of those biphasic alterations in the clotting mechanism.

There is evidence that immunosuppressive therapy with azathioprine and prednisone has a mitigating influence on the rejection process, despite which, chronic survival has not been obtained either in animals or in man. Nevertheless, potentiated survival of canine homografts was demonstrated. In the human cases, the transplanted livers were remarkably free from histologic stigmata of rejection after 6.5 to 23 days.

Dogs in which livers are transplanted heterotopically to the lower abdomen have distinct utility. Such experimental preparations have been used to study the vascular supply of the homografts, with the demonstration that the major arterial and venous radicals remained patent despite shrinkage of the organ and unequivocal histologic evidence of rejection. The low mortality with this technique makes evaluation of immunosuppressive therapy a more practical endeavor. Finally, the potential clinical application of this approach is suggested inasmuch as the host is not totally dependent upon homograft function during the rejection episodes which are to be expected during the postoperative period. In four dogs receiving such an auxiliary organ, second-stage removal of the recipient's own liver was carried out after 28 days. All animals died, presumably of hepatic insufficiency, within 48 hours. That some liver function was provided by the homograft is suggested by this limited survival, by the fact that two of the dogs awoke from pentobarbital anesthesia, and by the post-mortem absence of the intra-abdominal hemorrhage, which is characteristically found after total hepatectomy.

\section{References}

1. Starzl TE, Kaupp HA Jr, Brock DR, Lazarus RE, Johnson RV. Reconstructive problems in canine liver transplantation with particular reference to the postoperative role of hepatic venous flow. Surg Gynecol Obstet. 1960; 111:733. [PubMed: 18979655] 
2. Moore FD, Wheeler HB, Demissianos HV, Smith LL, Balankura O, Abel K, Greenberg JB, Dammin GJ. Experimental whole organ transplantation of the liver and of the spleen. Ann Surg. 1960; 152:374. [PubMed: 13772284]

3. Starzl TE, Kaupp HA Jr, Brock DR, Linman JW. Studies on the rejection of the transplanted homologous dog liver. Surg Gynecol Obstet. 1961; 112:135. [PubMed: 18979656]

4. Kukral JC, Littlejohn MH, Williams RK, Pancner RJ, Butz GW Jr, Starzl TE. Hepatic function after canine liver transplantation. A M A Arch Surg. 1962; 85:157. [PubMed: 14460400]

5. McBride RA, Wheeler HB, Smith LL, Moore FD, Dammin GJ. Homotransplantation of the canine liver as an orthotopic vascularized graft. Histologic and functional correlations during residence in the new host. Am J Pathol. 1962; 41:501. [PubMed: 19971018]

6. Brock DR, Starzl TE. Histopathologic alterations associated with the transplanted homologous dog liver. Exptl Mol Pathol. 1962; 1:187. [PubMed: 13873233]

7. Marchioro TL, Huntley RT, Waddell WR, Starzl TE. Extracorporeal perfusion for obtaining postmortem homografts. Surgery. 1963; 54:900. [PubMed: 14087127]

8. Goodrich EO, Welch HF, Nelson JA, Beecher TS, Welch CS. Homotransplantation of the canine liver. Surgery. 1956; 39:244. [PubMed: 13298971]

9. Starzl TE, Bernhard VM, Cortes N, Benvenuto R. Technique for one-stage hepatectomy in dogs. Surgery. 1959; 46:880. [PubMed: 13833877]

10. Starzl TE, Marchioro TL, von Kaulla K, Hermann G, Brittain RS, Waddell WR. Homotransplantation of the liver in humans. Surg Gynecol Obstet. 1963; 117:659. [PubMed: 14100514]

11. Starzl TE, Marchioro TL, Rifkind D, Rowlands DT, Waddell WR. Clinical experience with organ transplantation. Southern Med J. 1964 (in press).

12. Starzl TE, Marchioro TL, Hermann G, Brittain RS, Waddell WR. Renal homografts in patients with major donor-recipient blood group incompatibilities. (addendum). Surgery. 1964; 55:195. [PubMed: 14121762]

13. Starzl TE, Marchioro TL, Holmes J, Waddell WR. The incidence, cause, and significance of immediate and delayed oliguria or anuria after human renal transplantation. Surg Gynecol Obstet. 1964; 118:819. [PubMed: 14141329]

14. Jacob HS, MacDonald RA, Jandl JH. The regulation of spleen growth and sequestering function. $\mathrm{J}$ Clin Invest. 1962; 41:1367.

15. Sicular A, Dreiling DA, Paronetto F, Kark AE. Studies of rejection of the homotransplanted canine liver. Surg Forum. 1963; 14:202. [PubMed: 14064518]

16. Sicular A, Moore FD. The postmortem survival of tissues. I. A standardized glucose oxidation procedure for assessing tissue viability after death of the host. J Surg Res. 1961; 1:9.

17. Sicular A, Moore FD. The postmortem survival of tissues. II. The effect of time and temperature on the survival of liver as measured by glucose oxidation rate. J Surg Res. 1961; 1:16.

18. Starzl TE, Butz GW Jr, Brock DR, Linman JT, Moss WT. Canine liver homotransplants: The effect of host and graft irradiation. A M A Arch Surg. 1962; 85:460. [PubMed: 13916391]

19. Green HSN. The heterologous transplantation of embryonic mammalian tissues. Cancer Res. 1943; 3:809.

20. Starzl TE, Marchioro TL, Waddell WR. The reversal of rejection in human renal homografts with subsequent development of homograft tolerance. Surg Gynecol Obstet. 1963; 117:385. [PubMed: 14065716] 


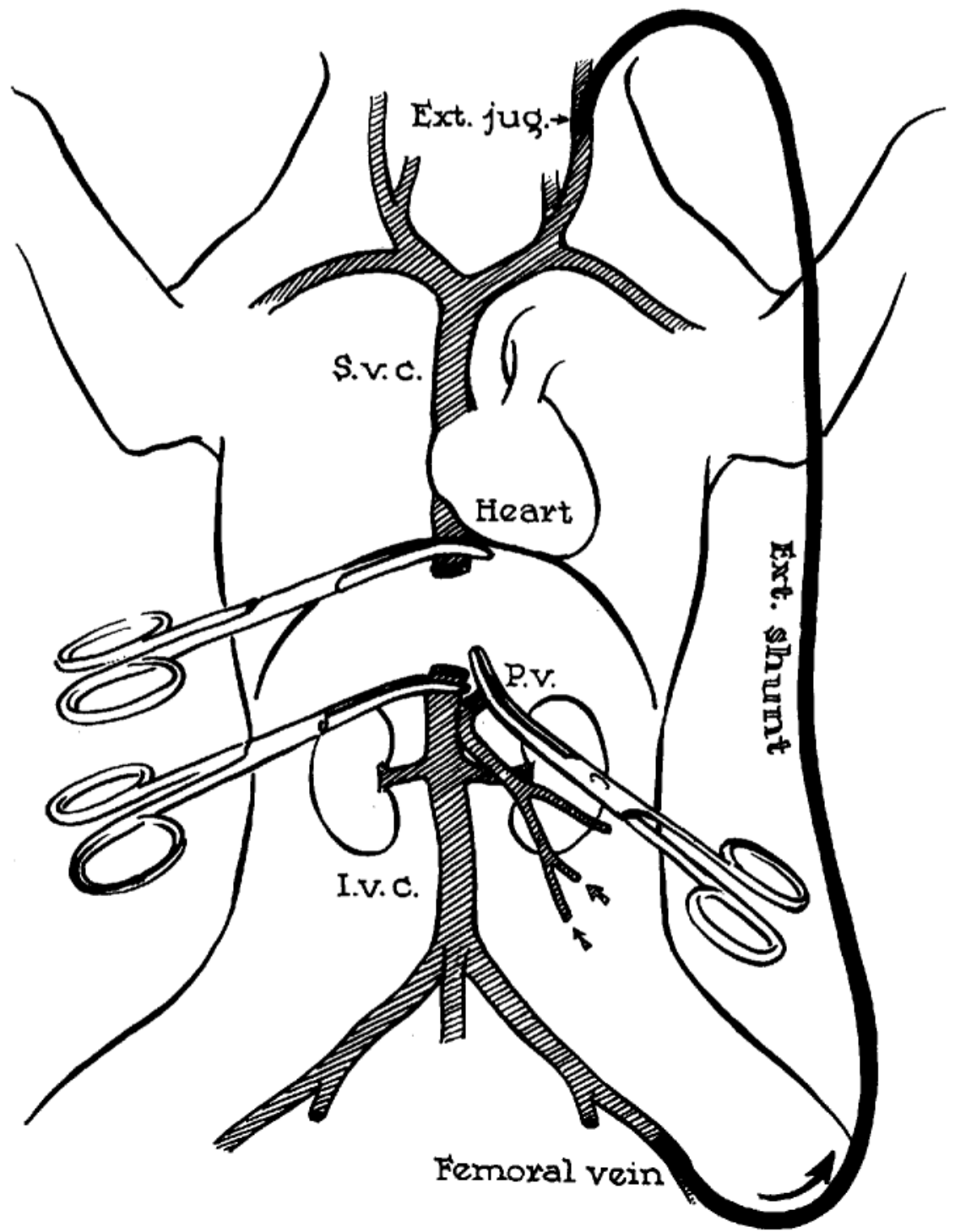

Figure 1.

By-pass system employed during orthotopic homotransplantation of the canine liver. A temporary side-to-side portacaval shunt is performed to bring the splanchnic and systemic venous pools into communication. A single plastic external by-pass is then used to decompress both systems during the period of necessary venous occlusion. The portacaval anastomosis is later taken down and lateral repair of the two vessels is carried out. (By permission of Surgery, Gynecology \& Obstetrics. 111: 733. 1960.) 


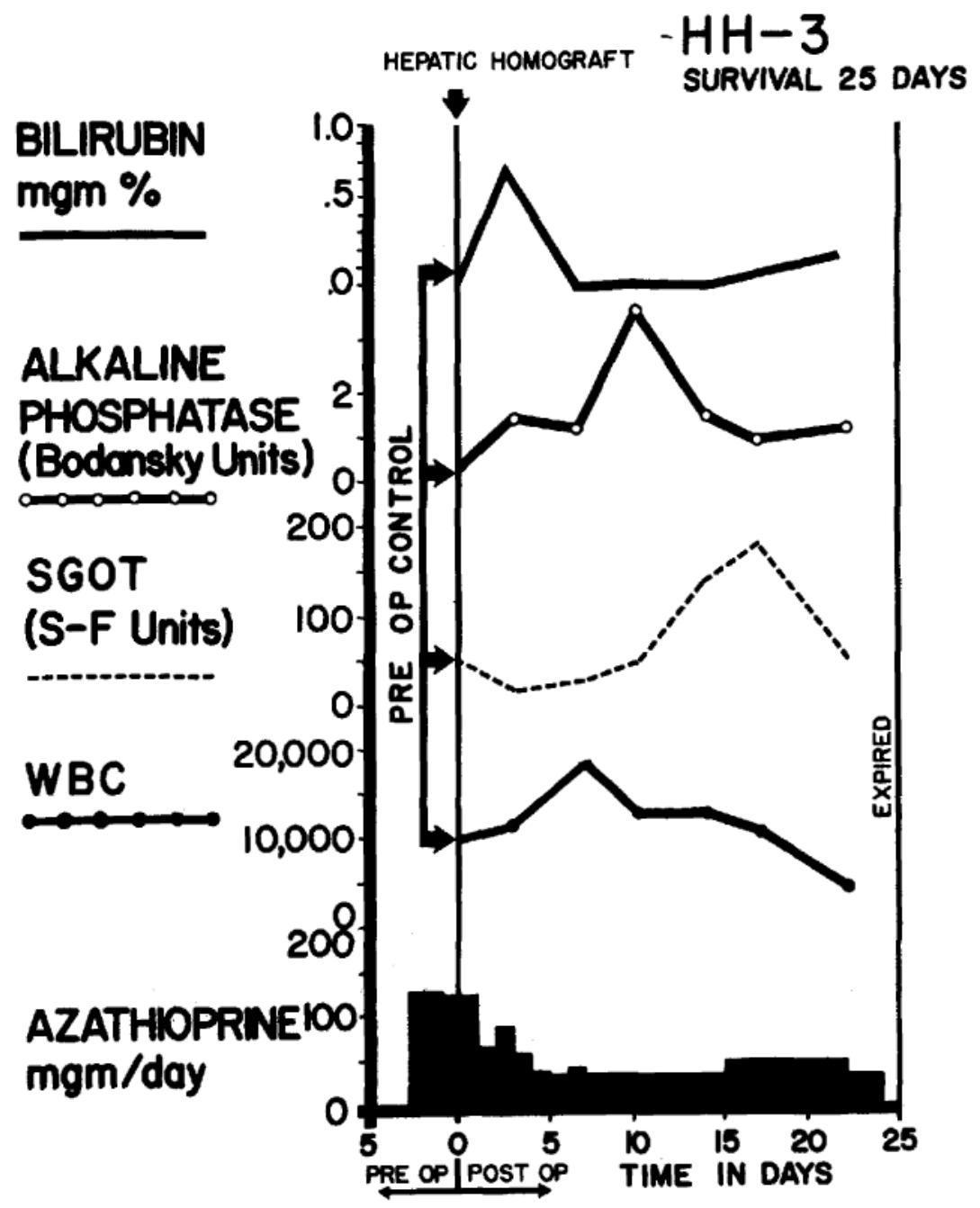

Figure 2.

Course of dog receiving total hepatectomy and orthotopic liver homograft. Note that the only unequivocal abnormality in the chemistries was a rise in SGOT during the third week which had returned to normal before death. The animal was reexplored for liver biopsy on the 24th postoperative day, and did not awake from anesthesia. The cause of death was pneumonia. 


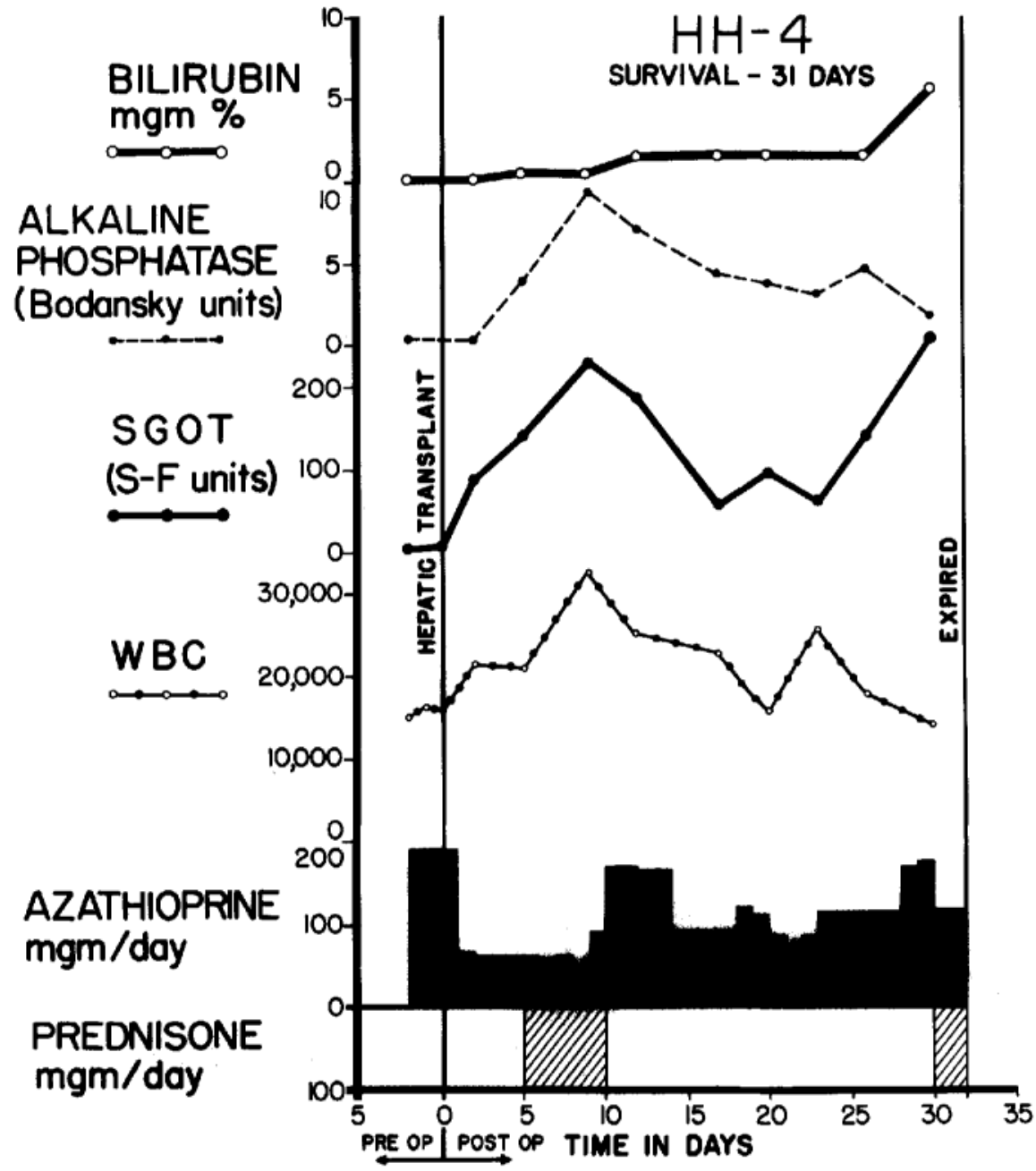

Figure 3.

Canine orthotopic liver homograft. Note the early rise in alkaline phosphatase and SGOT which appeared to have been reversed during the added administration of prednisone. Terminally, the animal became jaundiced. The primary cause of death was a perforated gastric ulcer, although pneumonia and a pulmonary embolus were also found. 

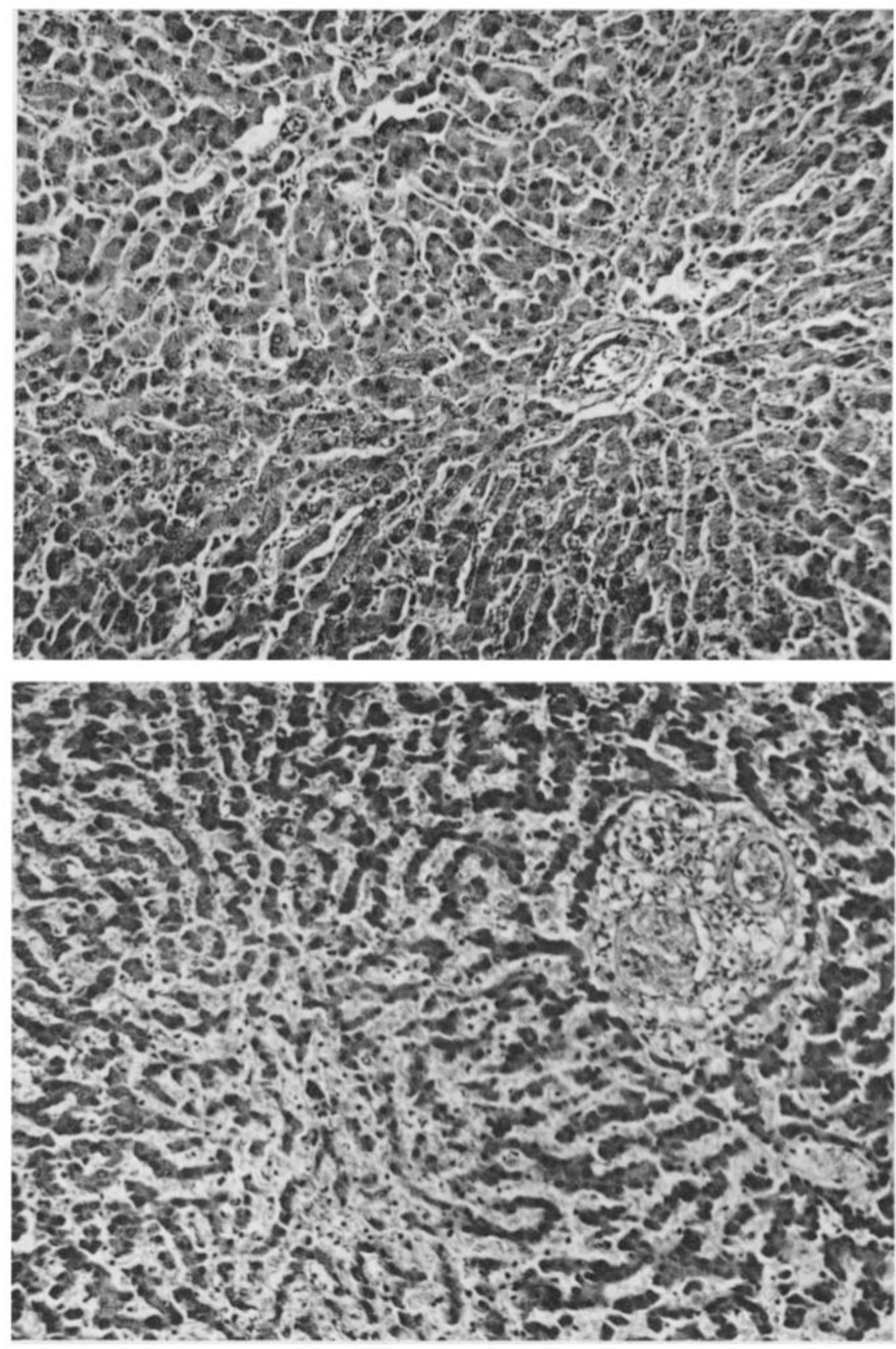

Figure 4.

Orthotopic hepatic homografts from dogs who died early in the postoperative course, $(a$, above) Dog No. 17, died of pneumonia after five days. Note absence of cellular infiltrate. (b) Dog. No. 18, who died of pneumonia nine days after operation. Note small numbers of mononuclear cells in portal areas, and central congestion. $\mathrm{H} \& \mathrm{E}$ stain $(\times 80)$. 

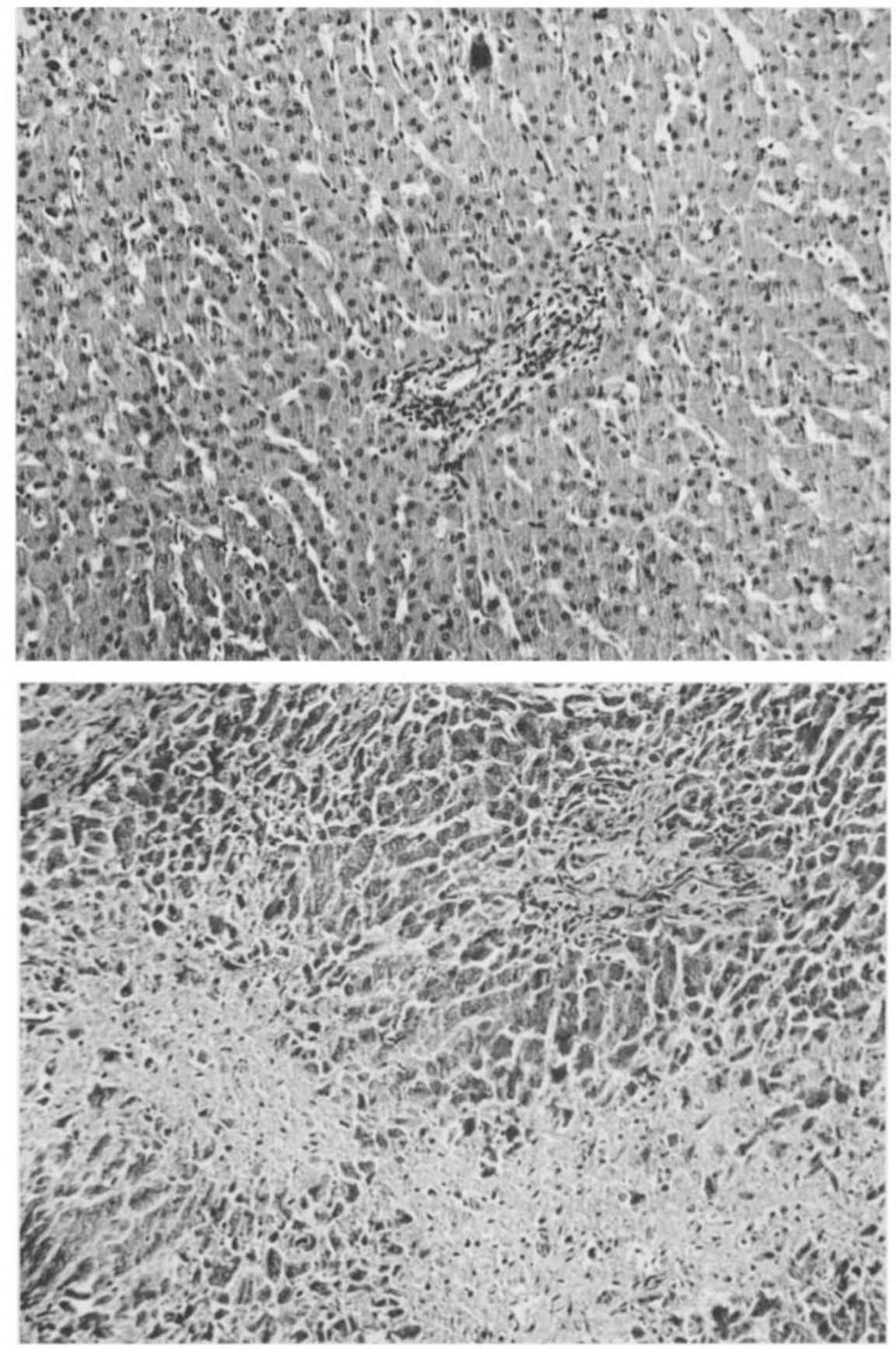

Figure 5.

Orthotopic hepatic homografts in dogs with delayed mortality, (a, above) Dog No. 3, died of pneumonia and pulmonary edema 25 days postoperatively. A few mononuclear cells are in the portal area. (b) Dog No. 4, who died of a perforated gastric ulcer, pneumonia, and a pulmonary embolus, 31 days postoperatively. The areas of parenchymal loss in the lower field contain a few strands of fibrous tissue. Portal areas have small numbers of mononuclear cells. H \& E stain $(\times 80)$. 


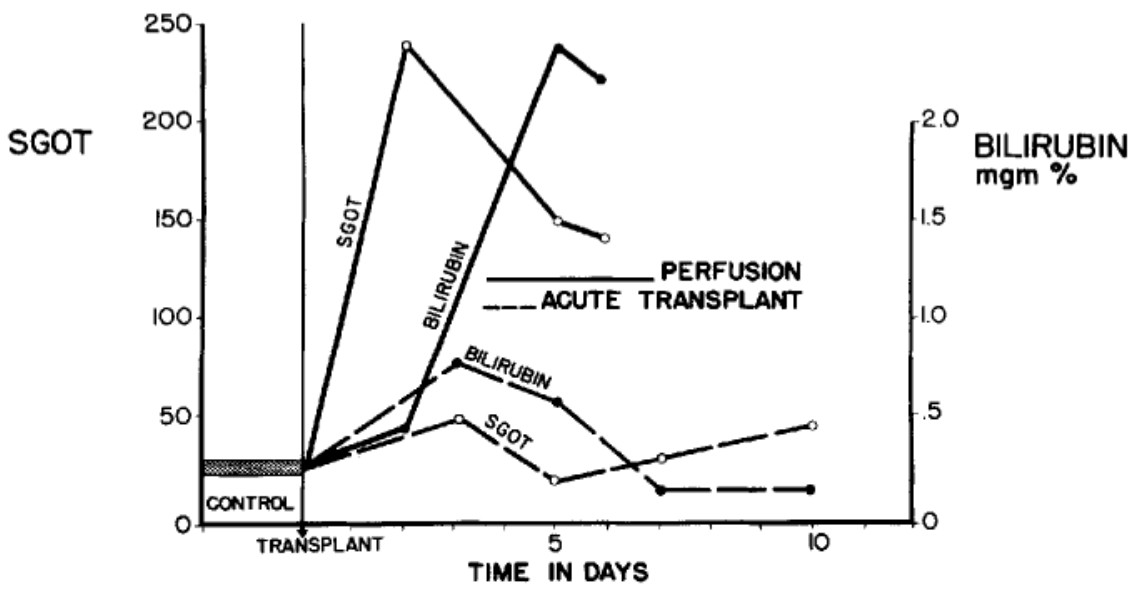

Figure 6.

Orthotopic canine liver homotransplantations, showing the difference in behavior with cadaveric and with living donors. The dog treated with a living donor (solid lines) had minimal changes in SGOT and bilirubin. The animal which received a cadaveric transplant (dashed lines) had marked rises in serum SGOT and bilirubin. The latter animal died in five and one-half days. (By permission of Surgery. 54: 900. 1963.) 


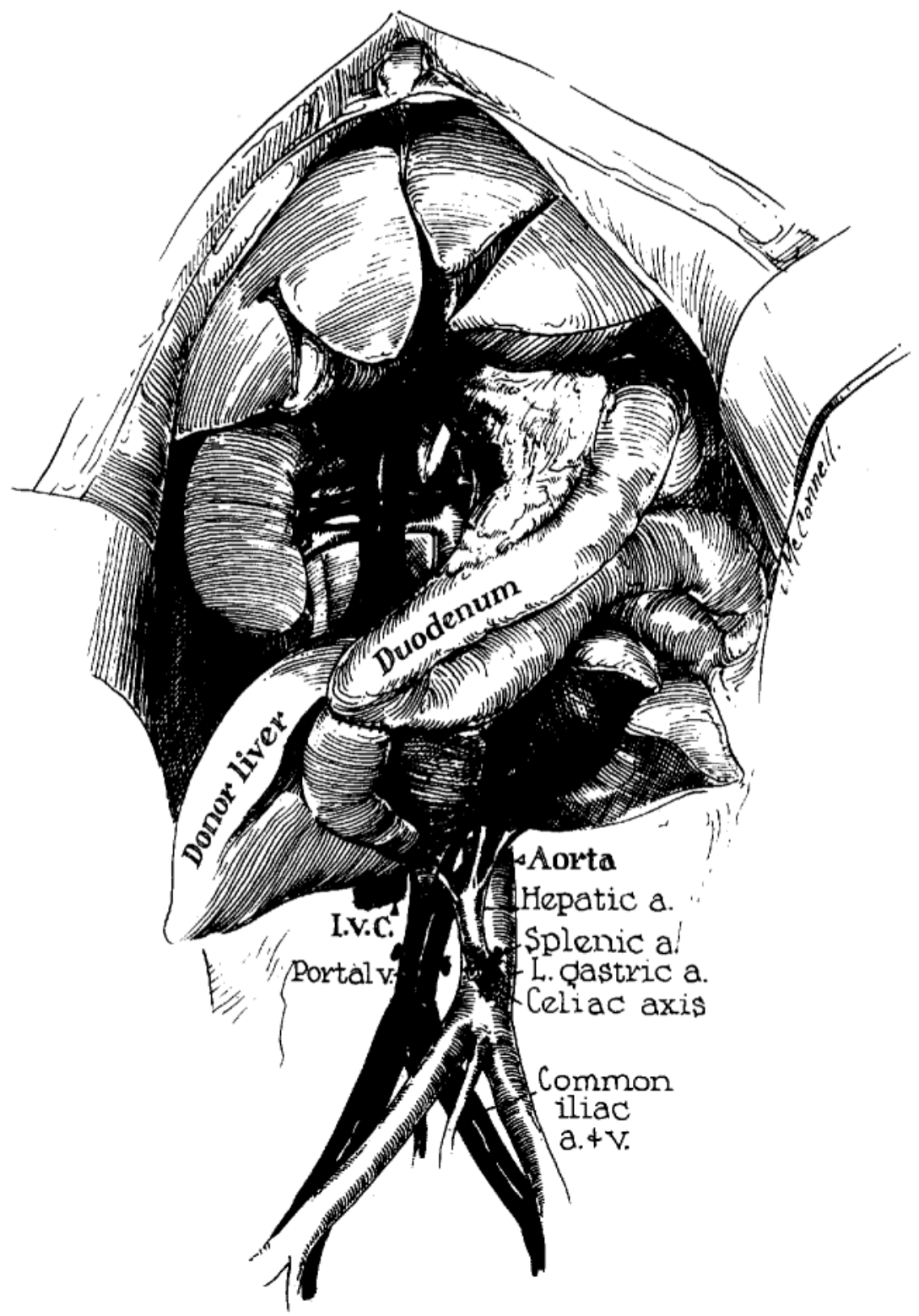

Figure 7.

Technique of auxiliary liver homotransplantation. The coeliac axis is connected to the terminal aorta as shown, or end-to-end and to the left common iliac artery. Interposition of the venous inflow and outflow into the inferior vena caval system is evident. 

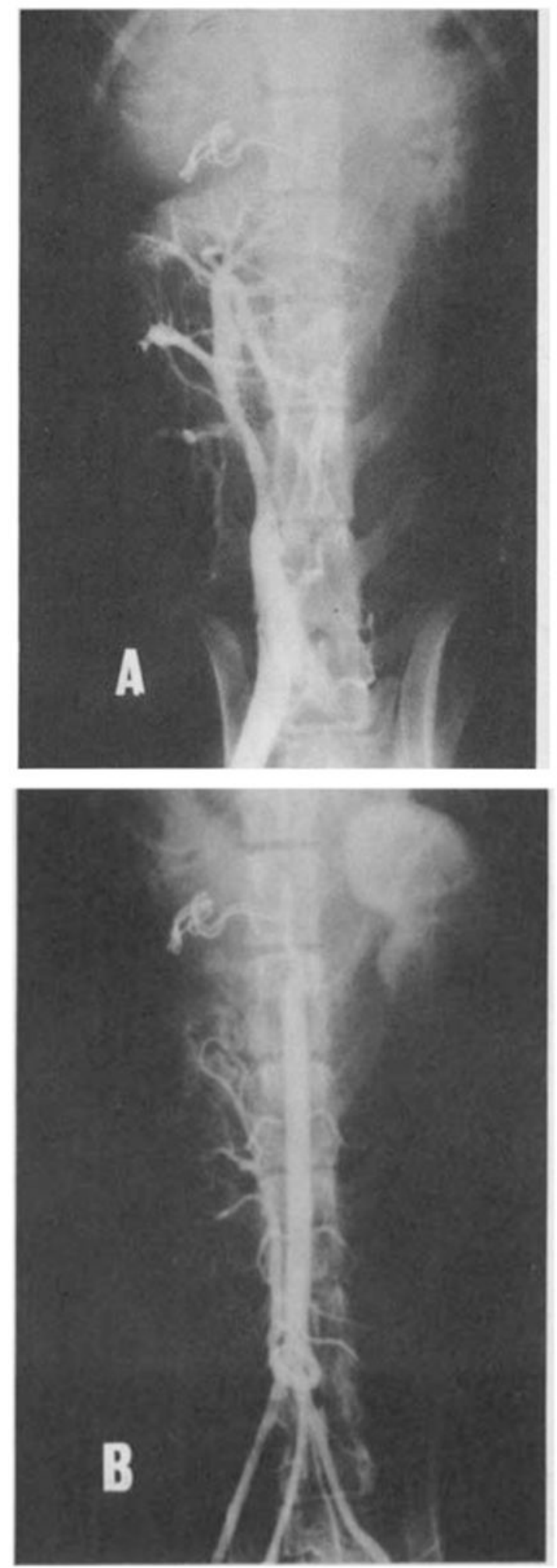

Figure 8.

Angiographic studies of AHH-3. (A, above) Portogram obtained with transfemoral dye injection. (B) Hepatic arterial circulation determined with retrograde transfemoral 
aortography. The left external iliac artery was attached end-to-end to the hepatic artery. Note the excellent filling of small peripheral branches of both the arterial and venous systems. 

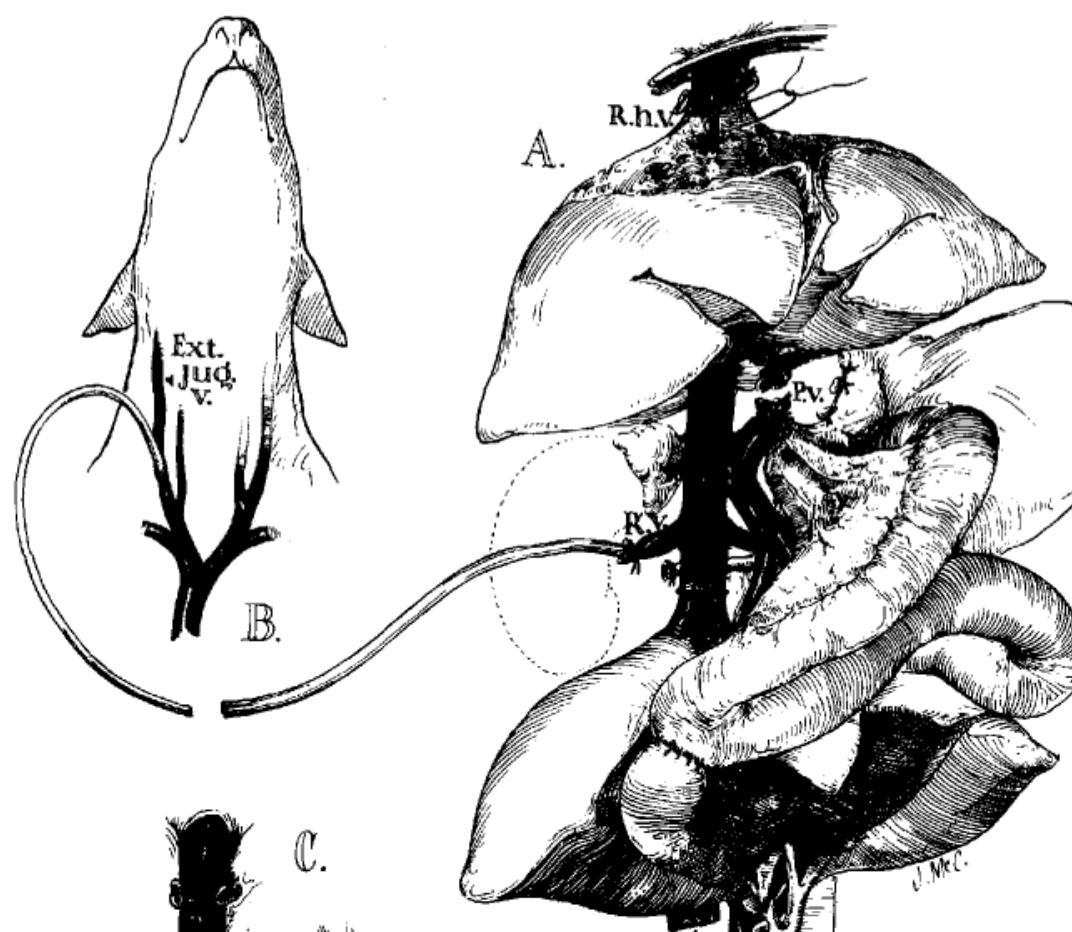

L.
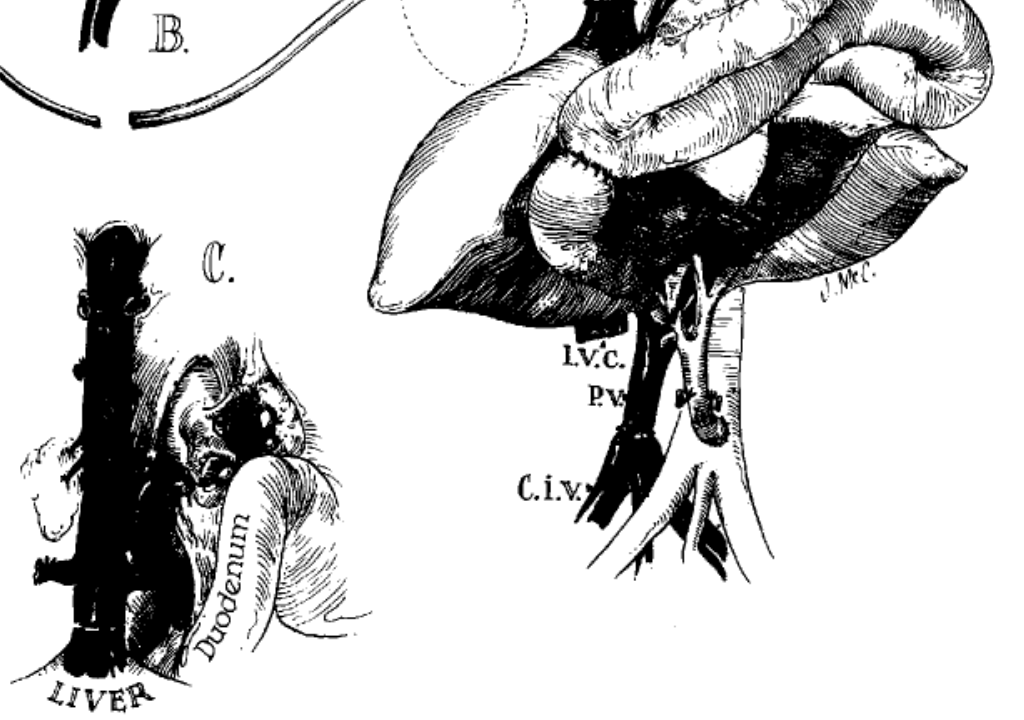

Figure 9.

Second-stage removal of recipient's own liver after auxiliary liver homotransplantation. In some cases, hepatectomy was performed without the aid of an external by-pass. After this operation, the homograft is the only remaining hepatic tissue. 


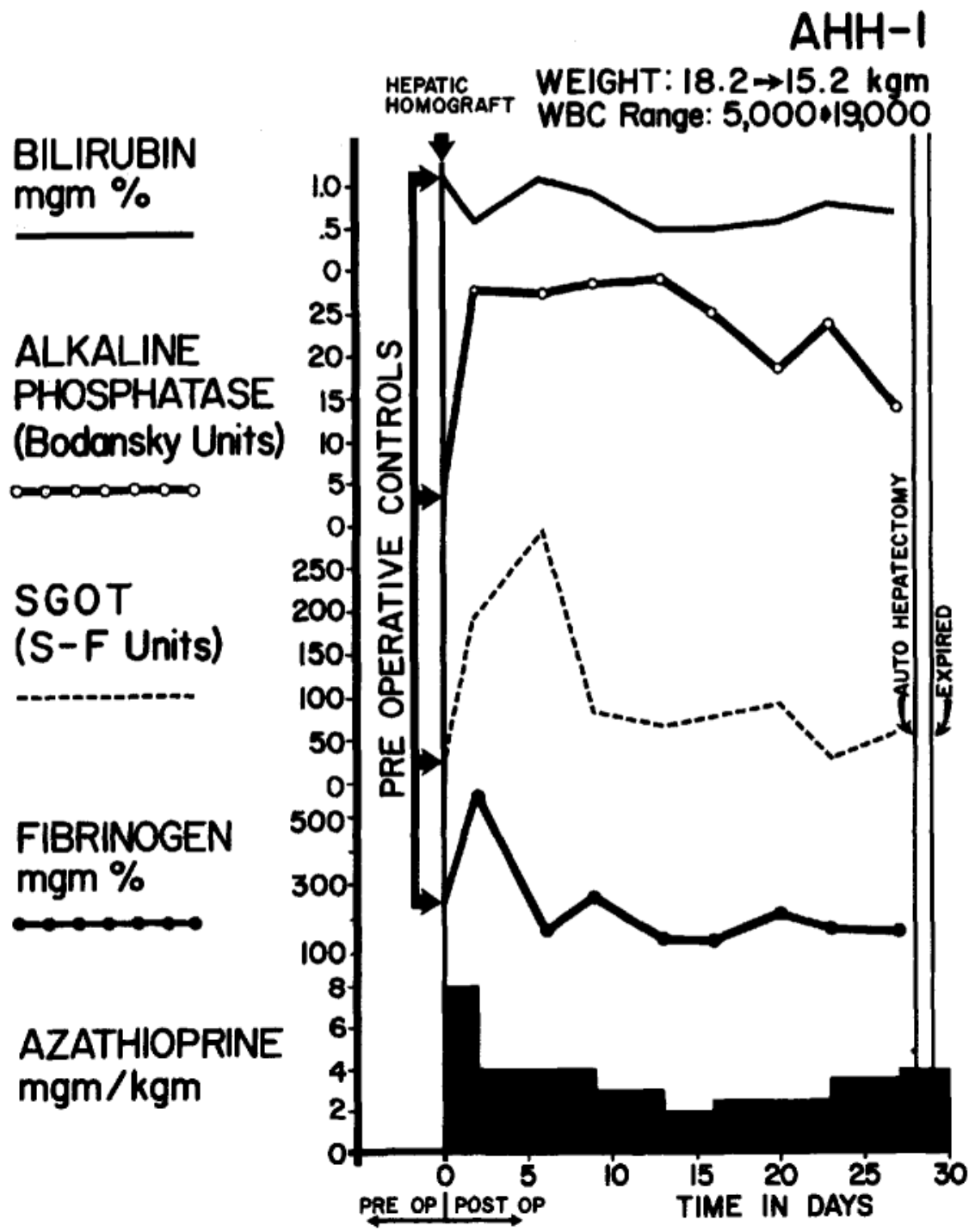

Figure 10.

Biochemical changes observed in animals with heterotopic hepatic homotransplantation without removal of the recipient's own liver. Rises in alkaline phosphatase and SGOT tended to be higher than those observed with orthotopic transplantation and concomitant host hepatectomy. Note the sharp rise in fibrinogen during the early postoperative period, a finding observed in every animal. 

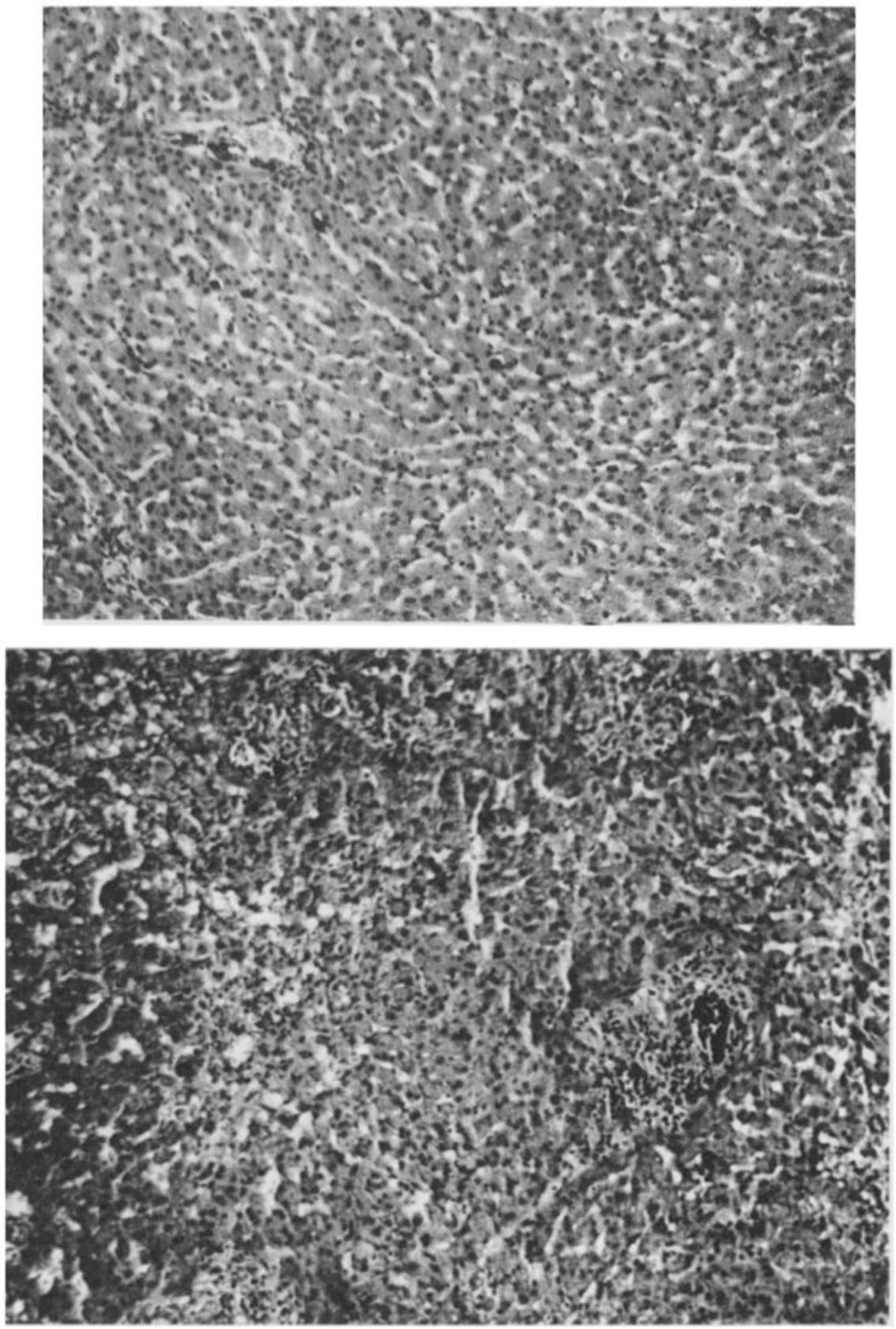

Figure 11.

Host and homografted liver 28 days after auxiliary hepatic homotransplantation. (a, above) Recipient dog's own liver which is essentially normal. (b) Homograft which was revascularized in the lower abdomen. Note the moderate amount of cellular infiltrate of the portal area. The parenchyma has many areas of focal necrosis. Total removal of the recipient animal's own liver was carried out at the time of these biopsies. The heterotopic transplant did not sustain life, and the dog died two days later. H \& E stain $(\times 80)$. 


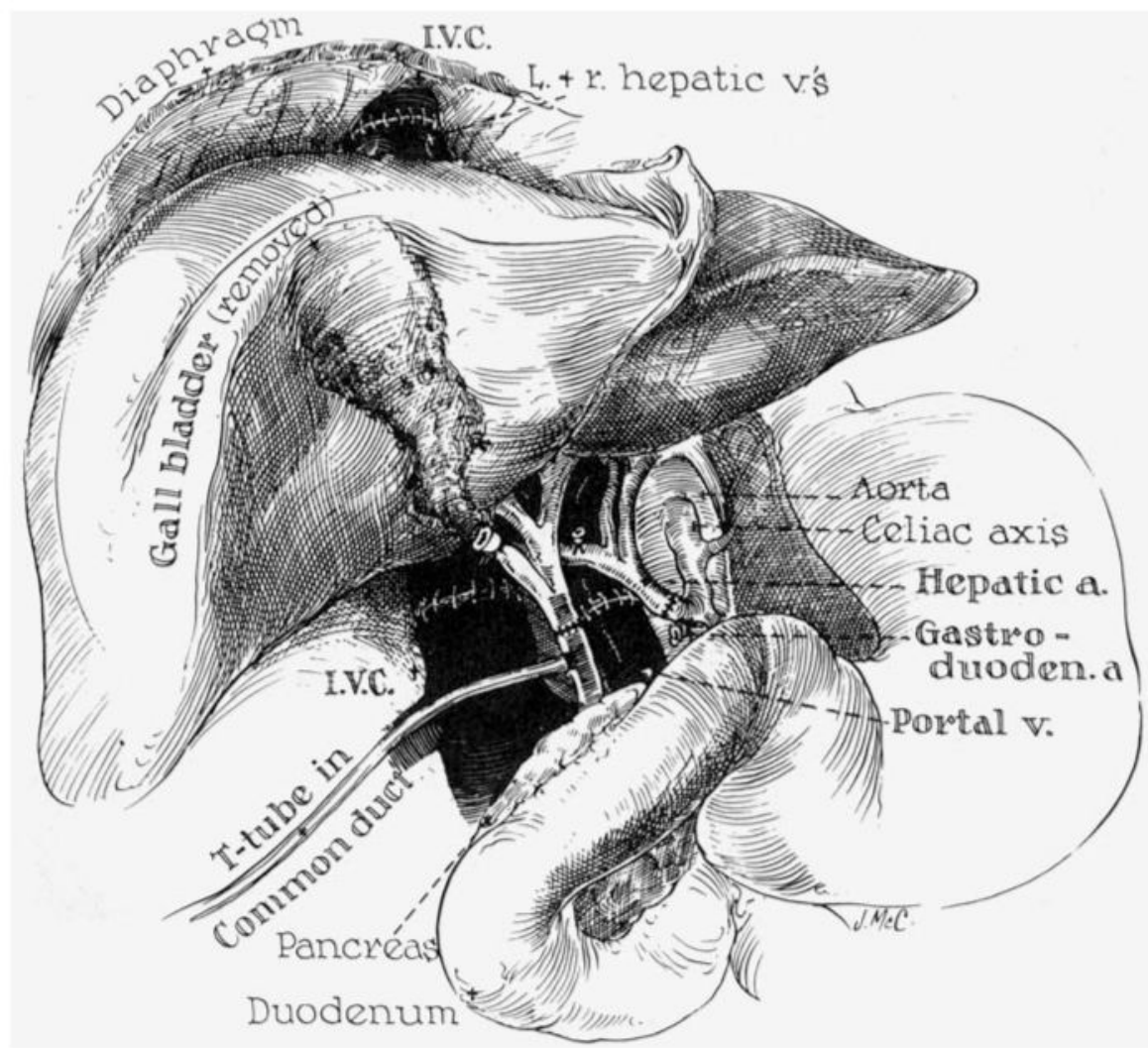

Figure 12.

Anastomotic connections in orthotopic human hepatic homotransplantation. Note that the Ttube is inserted through the recipient portion of the reconstructed common duct. 


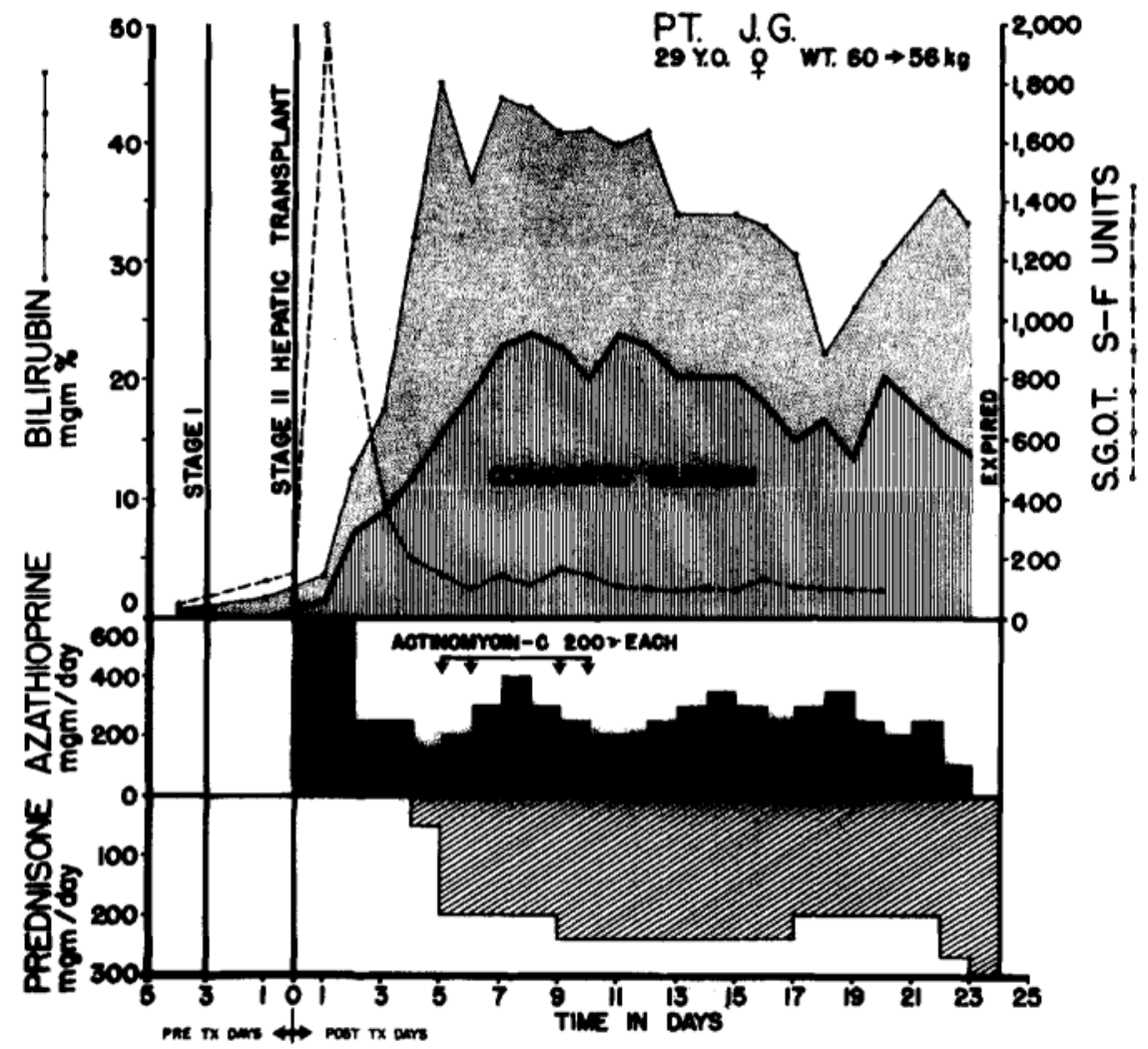

Figure 13.

Orthotopic liver homotransplantation in a patient with a primary hepatoma. Note the early rises in SGOT and bilirubin with later partial reversal of these abnormalities. On the 17th postoperative day, the patient developed abdominal pain after which her condition deteriorated. A secondary rise in bilirubin began at this time. At autopsy, 23 days after operation, the donor portion of the reconstructed common bile duct had necrosed and bile peritonitis was present. Immunosuppressive therapy is depicted at the bottom of the chart. 

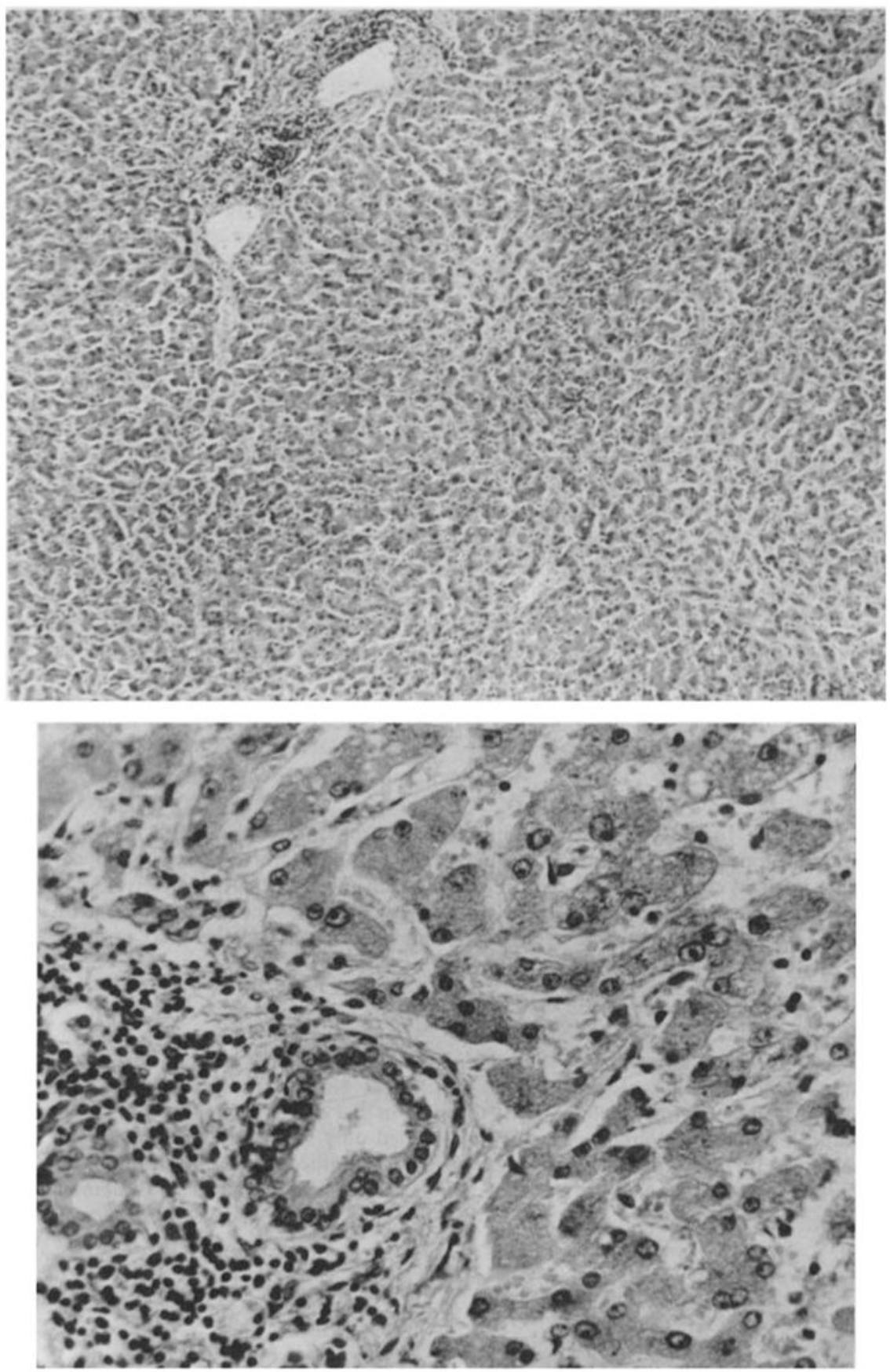

Figure 14.

Orthotopic human hepatic homograft obtained at autopsy in Case 4, six and one-half days after operation, (a, above) Low power view showing intact architecture and accumulation of cells in portal area. $\mathrm{H} \& \mathrm{E}$ stain $(\times 32)$. (b) High power showing focal cellular infiltrate in portal area. H \& E stain $(\times 160)$. 

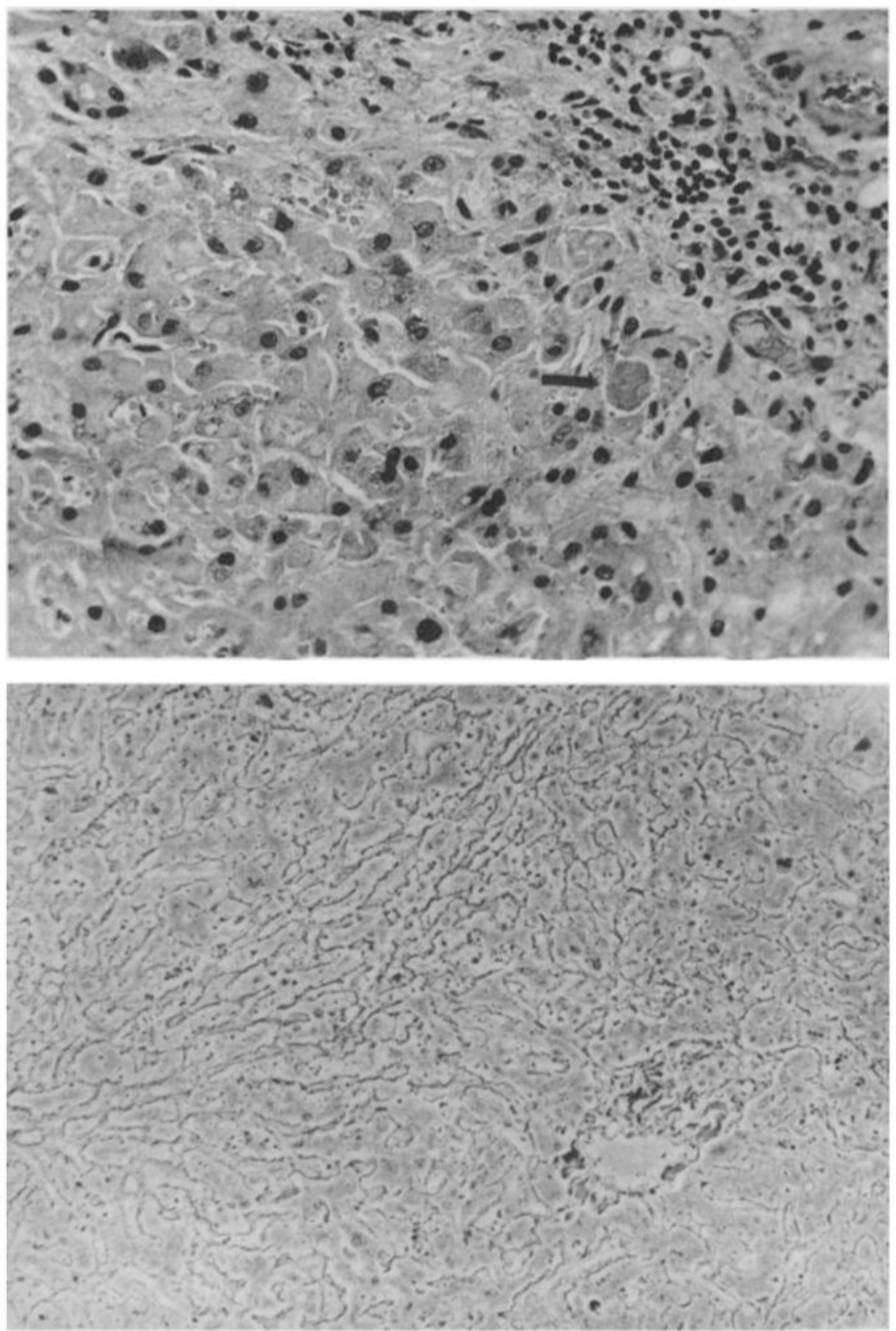

Figure 15.

Hepatic homograft from patient 5, 23 days after operation, (a, above) High power view of portal area showing mononuclear cellular infiltrate and well preserved adjacent hepatocytes. There was evidence of cholestasis in this and one other human homograft from patients who survived the acute effects of operation. Bile accumulates within the liver (arrow) were found in the homograft of Case 2. H \& E stain $(\times 160)$. (b) Same patient showing preservation of hepatic reticulum. Silver stain $(\times 80)$. 
Table 1

Orthotopic Canine Hepatic Homotransplants

\begin{tabular}{|c|c|c|c|c|}
\hline No. & Ischemia (min.) & Survival (days) & Cause of death & Histologic rejection \\
\hline 1 & 65 & 11 & Pneumonia & Moderate \\
\hline 2 & 75 & 1 & Outflow block; hemorrhage & Absent \\
\hline 3 & 62 & 25 & Pneumonia; pulmonary edema & Mild \\
\hline 4 & 52 & 31 & Pneumonia; pulmonary embolus; perforated gastric ulcer & Moderate \\
\hline 5 & 66 & 9 & Pneumonia; hepatic abscess & Mild \\
\hline 6 & 64 & 1 & Outflow block; hemorrhage & None \\
\hline 7 & 60 & 2 & Outflow block; hemorrhage & None \\
\hline 8 & 90 & 2 & Pneumonia & None \\
\hline 9 & 103 & 12 & Disrupted cholecystenterostomy & No tissue \\
\hline 10 & 82 & 1 & Outflow block; hemorrhage & None \\
\hline 11 & 106 & 0 & Outflow block; hemorrhage & None \\
\hline 12 & 66 & 12 & Intussusception & Mild \\
\hline 13 & 82 & 1 & Outflow block; hemorrhage & None \\
\hline 14 & 68 & 4 & Intussusception & No tissue \\
\hline 15 & 85 & 0 & Outflow block; hemorrhage & None \\
\hline 16 & 66 & 12 & Pneumonia & Mild \\
\hline 17 & 87 & 5 & Pneumonia & None \\
\hline 18 & 56 & 9 & Pneumonia & Moderate \\
\hline 19 & 56 & 3 & Pulmonary embolus & None \\
\hline 20 & 64 & 20 & Pneumonia & Moderate \\
\hline 21 & 75 & 1 & Outflow block; hemorrhage & None \\
\hline 22 & 54 & 9 & Pneumonia & Mild \\
\hline 23 & 63 & 2 & Outflow block; hemorrhage & None \\
\hline 24 & 55 & 7 & Pneumonia; hepatic abscess & No tissue \\
\hline 25 & 64 & 1 & Outflow block; hemorrhage & None \\
\hline
\end{tabular}


Table 2

Canine Hepatic HomoGrafts from Cadaveric Donors

\begin{tabular}{|c|c|c|c|c|}
\hline Dog no. & $\begin{array}{c}\text { Perfusion started post-mortem } \\
\text { (min.) }\end{array}$ & $\begin{array}{l}\text { Total time from death to revascularization } \\
\text { (hr., min.) }\end{array}$ & Survival post-transplant & Cause of death \\
\hline 1 & 7 & 2,3 & No & Hemorrhage \\
\hline 2 & 4 & 3,54 & No & Hemorrhage \\
\hline 3 & 5 & 4,22 & No & Hemorrhage \\
\hline 4 & Immediate & 3 & No & Hemorrhage \\
\hline 5 & 7 & 2,18 & 4 days & Bile peritonitis \\
\hline 6 & 8 & 3,38 & No & Hemorrhage \\
\hline 7 & 4 & 3,42 & 5 days & Intussusception \\
\hline 8 & Immediate & 8,18 & 2 days & Hemorrhage \\
\hline 9 & 5 & 4,55 & 3 days & Hemorrhage \\
\hline 10 & 22 & 4,47 & 24 hours & Hemorrhage \\
\hline
\end{tabular}




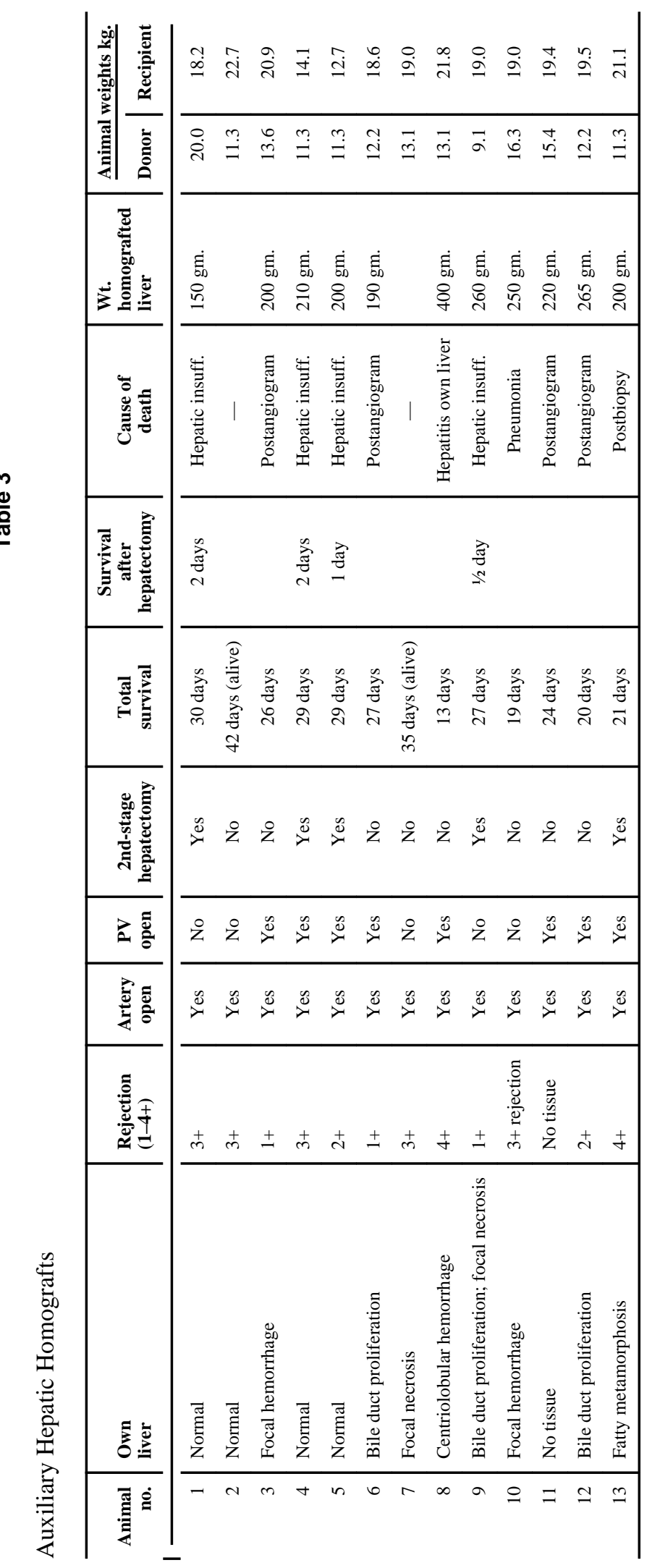


